\title{
CDISC SDTM Dictionary Name Terminology
}

National Cancer Institute

\section{Source}

National Cancer Institute. CDISC SDTM Dictionary Name Terminology. NCI Thesaurus.

Code C66788.

Terminology codelist used with Dictionary Name within the Clinical Data Interchange Standards Consortium Study Data Tabulation Model. 